Удк 615.072.32

\title{
ОПРЕДЕЛЕНИЕ ГИДРОКСИКОРИЧНЫХ КИСЛОТ, КАРОТИНОИДОВ И ХЛОРОФИЛЛА В ЛИСТЬЯХ КРАПИВЫ ДВУДОМНОЙ (URTICA DIOICA L.)
}

\author{
() О.В. Тринеева \\ Воронежский государственный университет, ул. Студенческая, 3, Воронеж, \\ 394006 (Россия), e-mail: trineevaov@mail.ru
}

В 2014 г. утверждена новая фармакопейная статья для включения в ГФ ХІІІ изд. «Крапивы двудомной листья», в которой по аналогии с Европейской фармакопеей предусмотрено количественное определение гидроксикоричных кислот в пересчете на кислоту хлорогеновую. Значение для листьев крапивы представляют такие биологически активные вещества, как витамин К, флавоноиды, гидроксикоричные кислоты, каротиноиды, дубильные вещества, аминокислоты, хлорофиллы и др. Листья крапивы двудомной богаты каротиноидами, максимум поглощения которых отчетливо виден на спектрах извлечений. За основу была взята ранее разработанная методика количественного определения гидроксикоричных кислот и хлорофилла в листьях крапивы двудомной методом спектрофотометрии. Однако вид спектра поглощения извлечения из анализируемого сырья свидетельствует о возможности одновременного определения не только данных биологически активных веществ, но и каротиноидов без предварительного разделения, поскольку их максимумы не накладываются. В работе проведена модификация методики количественного содержания гидроксикоричных кислот и хлорофилла в листьях крапивы двудомной методом спектрофотометрии, заключающаяся в дополнительном определении суммы каротиноидов в пересчете на виолоксантин при совместном присутствии. Исследовано влияние полярности экстрагента на извлечение изучаемых групп биологически активных веществ. Установлено, что с увеличением полярности до 6,0 единиц происходит повышение экстрагируемости всех изучаемых групп веществ. Установлены валидационные характеристики количественного определения каротиноидов по предложенной методике. Проведен сравнительный анализ полученных результатов с литературными данными по определению изучаемых групп биологически активных веществ различных видов растения рода Urtica ssp.

Ключевые слова: крапива двудомная, стандартизация, гидроксикоричные кислоты, хлорофилл, виолоксантин.

\section{Введение}

Листья крапивы двудомной являются официнальным лекарственным растительным сырьем (ЛРС) и входят в Государственный реестр лекарственных средств 2004 и 2008 гг., а также в ГФ VIII, IX и XI изд. в качестве кровоостанавливающего средства [1]. В части, касающейся ЛРС, отечественная ГФ не переиздавалась и не дополнялась с 1990 г. Стандартизация листьев крапивы до недавнего времени проводилась в соответствии с требованиями фармакопейной статьи ГФ XI изд. [2], в которой не было предусмотрено количественное определение какой-либо группы биологически активных веществ (БАВ). В 2014 г. утверждена новая фармакопейная статья для включения в ГФ ХІІІ изд. «Крапивы двудомной листья», в которой по аналогии с Европейской фармакопеей предусмотрено количественное определение гидроксикоричных кислот (ГКК) в пересчете на кислоту хлорогеновую.

Тринеева Ольга Валерьевна - кандидат фармацевтических наук, доцент кафедры фармацевтической химии и фармацевтической технологии, e-mail: trineevaov@mail.ru Сливкин Алексей Иванович - доктор фармацевтических наук, профессор, заведующий кафедрой фармацевтической химии и фармацевтической технологии, декан фармацевтического факультета, e-mail: slivkin@pharmvsu.ru

Сафонова Елена Федоровна - кандидат химических наук, доцент, заведующая кафедрой фармации последипломного образования,

e-mail: safonova@pharmvsu.ru
Одним из ключевых вопросов является вопрос выбора группы БАВ для оценки качества ЛРС. Стандартизацию листьев крапивы, которые оказывают кровоостанавливающее действие, следовало бы проводить по содержанию витамина К [3, 4]. Разработана методика хроматоспектрофотометрического определения витамина К в листьях крапивы коноплевой [5]. По литературным данным, другие попытки с помощью спектральных и колометрических методик определить витамин К не дали достоверных и воспроизводимых результатов [3].

\footnotetext{
* Автор, с которым следует вести переписку.
} 
Значение для листьев крапивы, наряду с витамином К, представляют такие БАВ, как флавоноиды, ГКК, каротиноиды, дубильные вещества, аминокислоты, витамины, хлорофиллы и другие, обусловливающие фармакологические свойства данного сырья [6]. По данным авторов [6], ЛРС и препараты крапивы в официнальной медицине применяют не только как кровоостанавливающее, но и как гипотензивное, анальгетическое и мочегонное средства, при кожных, бронхолегочных, гинекологических, неврологических и других заболеваниях.

Известными учеными Сибирского государственного медицинского университета совместно с Первым Московским государственным медицинским университетом им. И.М. Сеченова разработана и валидирована методика количественного определения суммы хлорофиллов и ГКК в листьях крапивы двудомной. Однако в способе не обоснован выбор оптимального экстрагента для извлечения определяемых веществ из изучаемого сырья. Кроме того, листья крапивы двудомной богаты каротиноидами, максимум поглощения которых отчетливо виден на спектрах извлечений. Поэтому в данной работе изучена возможность одновременного определения ГКК, каротиноидов и хлорофилла в листьях крапивы прямым спектрофотометрическим методом без предварительного разделения за одну аналитическую процедуру.

Цель исследования - разработка методики количественного определения ГКК, хлорофилла и каротиноидов при совместном присутствии в листьях крапивы двудомной методом прямой спектрофотометрии.

\section{Экспериментальная часть}

В качестве объекта исследования использовали измельченное сырье листьев крапивы двудомной одного отечественного производителя (серия 010313).

Электронные спектры поглощения измеряли на спектрофотометре СФ-2000 (РФ) в кварцевых кюветах с толщиной поглощающего слоя 10 мм в диапазоне волн 200-800 нм. При изучении спектральных характеристик извлечений из листьев крапивы двудомной, полученных с применением различных экстрагентов (вода, водно-спиртовые смеси различной концентрации, ацетон), наблюдали основные максимумы поглощения в области $323 \pm 5$ нм, характерные для ГКК [3] 442 2 нм, характерные для каротиноидов (виолоксантин) [7] и 667士3 нм, свойственные для хлорофилла [3, 7-10] (рис. 1).

Выбор экстрагента осуществляли на основании полученных данных по влиянию полярности растворителя на извлечение БАВ (рис. 2). Установлено, что с увеличением полярности до 6,0 единиц происходит повышение экстрагируемости всех изучаемых групп БАВ. Дальнейшее увеличение полярности экстрагента нецелесообразно ввиду снижения их содержания в извлечении. Оптимальным экстрагентом является 70\% этанол.

В работе за основу была взята ранее разработанная методика количественного определения ГКК и хлорофилла в листьях крапивы двудомной методом спектрофотометрии [3]. Однако вид спектра поглощения извлечения из анализируемого ЛРС (рис. 1) свидетельствует о возможности одновременного определения не только ГКК и хлорофилла, но и каротиноидов без предварительного разделения, поскольку их максимумы не накладываются. Согласно литературным данным максимумы поглощения экстракта листьев крапивы на $70 \%$ этаноле совпадают с максимумами поглощения стандартных образцов хлорогеновой ки-

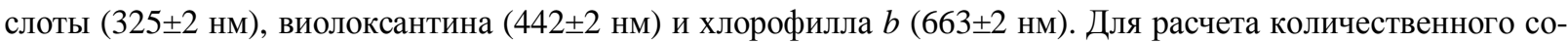
держания изучаемых групп БАВ использовали значения удельных показателей поглощения, представленные в литературе [3, 7].

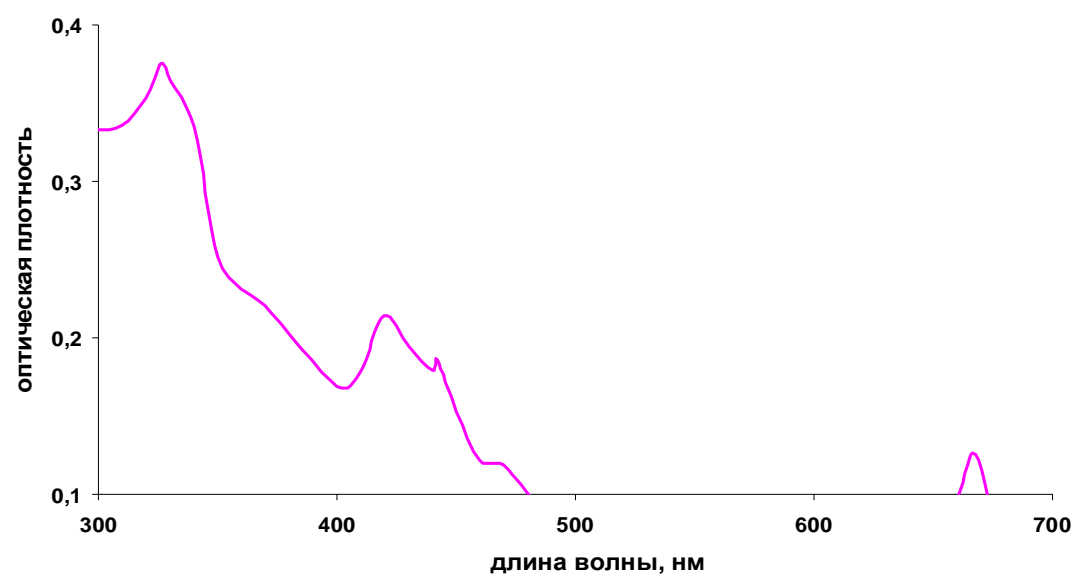

Рис. 1. Спектр поглощения извлечения из листьев крапивы двудомной 


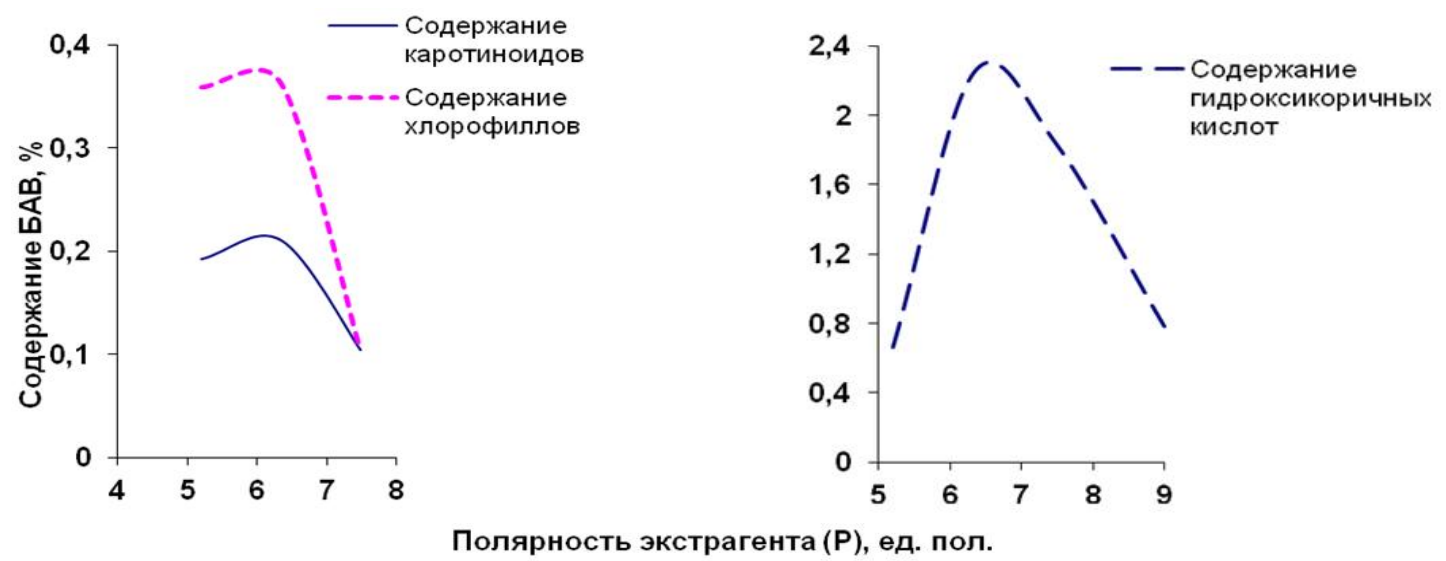

Рис. 2. Влияние полярности экстрагента на извлечение изучаемых групп БАВ

Количественное определение. Около 0,5 г (точная навеска) сырья, измельченного до размера частиц, проходящих сквозь сито с отверстиями диаметром 1 мм, помещали в плоскодонную колбу со шлифом вместимостью 100 мл и экстрагировали 50 мл 70\% этилового спирта в течение 30 мин. После охлаждения извлечение декантировали и фильтровали через бумажный фильтр в мерную колбу вместимостью 100 мл. Остаток в колбе заливали 50 мл 70\% этилового спирта и экстрагировати еще раз в течение 30 мин. Объединенные извлечения в мерной колбе доводили $70 \%$ этиловым спиртом до метки (раствор А). 2 мл раствора А переносили в мерную колбу вместимостью 25 мл и доводили объем 95\% этиловым спиртом до метки (раствор Б). Оптическую плотность полученного раствора измеряли на спектрофотометре СФ-2000 (РФ)

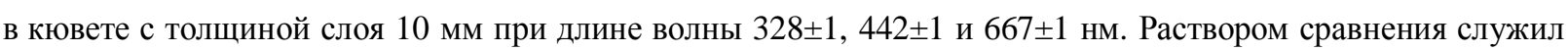
95\% этиловый спирт. Содержание суммы ГКК (в пересчете на хлорогеновую кислоту), каротиноидов (в пересчете на виолоксантин) и хлорофилла в процентах (X) в пересчете на абсолютно сухое сырье вычисляли по формулам (1-3) соответственно:

$$
\begin{gathered}
X, \%=\frac{A \cdot W_{1} \cdot W_{2} \cdot 100 \% \cdot 100 \%}{m \cdot E_{1 c M}{ }^{1 \%} \cdot 100 \cdot V_{a} \cdot(100 \%-B \%)}=\frac{A \cdot 100 \cdot 25 \cdot 100 \cdot 100}{m \cdot 507 \cdot 100 \cdot 2 \cdot(100-B)}=\frac{A \cdot 250000}{m \cdot 507 \cdot 2 \cdot(100-B)} ; \\
X, \%=\frac{A \cdot W_{1} \cdot W_{2} \cdot 100 \% \cdot 100 \%}{m \cdot E_{1 c M}{ }^{1 \%} \cdot 100 \cdot V_{a} \cdot(100 \%-B \%)}=\frac{A \cdot 100 \cdot 25 \cdot 100 \cdot 100}{m \cdot 2500 \cdot 100 \cdot 2 \cdot(100-B)}=\frac{A \cdot 100}{m \cdot 2 \cdot(100-B)} ; \\
X, \%=\frac{A \cdot W_{1} \cdot W_{2} \cdot 100 \% \cdot 100 \%}{m \cdot E_{1 c M}{ }^{1 \%} \cdot 100 \cdot V_{a} \cdot(100 \%-B \%)}=\frac{A \cdot 100 \cdot 25 \cdot 100 \cdot 100}{m \cdot 944,5 \cdot 100 \cdot 2 \cdot(100-B)}=\frac{A \cdot 250000}{m \cdot 944,5 \cdot 2 \cdot(100-B)},
\end{gathered}
$$

где $A$ - оптическая плотность раствора Б в соответствующем максимуме поглощения; $m$ - масса сырья, г; $B$ - потеря в массе при высушивании сырья, \%; $E_{1 \text { см }}{ }^{1 \%}$ - удельный показатель поглощения, равный 507 для

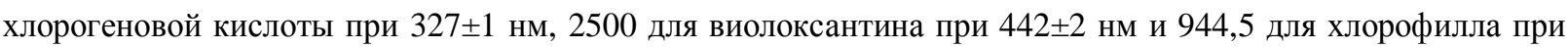
$663 \pm 5$ нм; $W_{1}$ и $W_{2}$ - объемы мерных колб, использованных для разведения, мл; $V_{\text {a }}$ объем аликвоты, взятый на анализ, мл.

\section{Обсуждение результатов}

Поскольку в методику [3] введено дополнительное количественное определение суммы каротиноидов, были установлены такие валидационные характеристики, как повторяемость и точность. Валидационные характеристики определения суммы ГКК и хлорофилла приведены в работе [3]. Результаты представлены в таблицах 1 и 2.

Точность методики устанавливали на девяти образцах и трех уровнях концентраций. Для оценки полученных результатов наглядным критерием служит открываемость $(R)$. При проведении анализа установлено среднее значение $R$ (табл. 2). 
Таблица 1. Результаты исследования повторяемости методики спектрофотометрического определения суммы каротиноидов в присутствии ГКК и хлорофиллов в листьях крапивы двудомной

\begin{tabular}{c|c|c}
\hline \multirow{2}{*}{ Проба } & \multicolumn{2}{|c}{ Каротиноиды } \\
\cline { 2 - 3 } & $X, \%$ & Результаты \\
\hline 1 & 0,1942 & $\mathrm{x}_{\mathrm{cp}} \pm \Delta \mathrm{x}_{\mathrm{cp}}=0,2098 \pm 0,0094 ;$ \\
2 & 0,2087 & $\mathrm{SD}=0,009 ;$ \\
3 & 0,2062 & $\mathrm{RSD}=4,29 \%$ \\
4 & 0,2137 & \\
5 & 0,2180 & \\
6 & 0,2180 & \\
\hline
\end{tabular}

Таблица 2. Результаты исследования точности методики спектрофотометрического определения суммы каротиноидов в присутствии ГКК и хлорофиллов в листьях крапивы двудомной

\begin{tabular}{|c|c|c|c|c|}
\hline Навеска ЛРС & Найдено, \% & $\begin{array}{c}\text { Расчетное } \\
\text { содержание, \% }\end{array}$ & $R, \%$ & $\begin{array}{c}\text { Метрологические } \\
\text { характеристики }\end{array}$ \\
\hline $\begin{array}{c}0,1220 \\
0,1200 \\
0,1221 \\
0,5000 \\
0,4937 \\
0,50155 \\
1,0000 \\
1,0010 \\
0,9991\end{array}$ & $\begin{array}{c}0,2137 \\
0,2184 \\
0,2087 \\
0,2159 \\
0,2023 \\
0,2180 \\
0,2027 \\
0,2062 \\
0,1942 \\
\mathrm{x}_{\mathrm{cp}}=0,2098\end{array}$ & 0,2098 & $\begin{array}{c}102,30 \\
104,55 \\
99,90 \\
103,35 \\
96,84 \\
104,36 \\
97,03 \\
98,71 \\
92,96 \\
\mathrm{R}_{\mathrm{cp}}=100,00\end{array}$ & $\begin{array}{c}\mathrm{SD}=0,00829 \\
\mathrm{RSD}=3,97 \% \\
\varepsilon_{\text {cp. }}=3,12 \% \\
\mathrm{x}_{\text {cp. }} \pm \Delta \mathrm{x}= \\
0,2089 \pm 0,0065\end{array}$ \\
\hline
\end{tabular}

Статистическая обработка результатов позволила вычислить величину относительного стандартного отклонения RSD. Согласно результатам (табл. 1 и 2), полученные экспериментально и вычисленные теоретически значения суммы каротиноидов практически полностью совпадают. $R$ для каротиноидов $-100,00 \%$. Для более точной оценки сопоставили величины $R S D$, вычисленные при определении повторяемости и точности методики. Они близки по значениям (4,29 и 3,97\%).

Как видно из представленных данных, величина относительного отклонения - не более 5\%, что не превышает критериев приемлемости и свидетельствует о точности и прецизионности методики в условиях повторяемости. Данные валидационной оценки методики свидетельствуют о возможности ее использования для стандартизации и оценки качества листьев крапивы. Новизна проведенных исследований подтверждена получением патента РФ на изобретение № 2531940 от 15.04.2013 [11].

Для оценки достоверности полученные результаты были сравнены с литературными данными по определению изучаемых групп БАВ различных видов растения рода Urtica ssp. [12-19] (табл. 3).

Таким образом, полученные экспериментальные данные сопоставимы с результатами исследований, проведенными другими авторами с использованием различных методик [12-19], что свидетельствует о достоверности определения изучаемых групп БАВ при модификации известной ранее методики.

Таблица 3. Содержание ГКК, каротиноидов и хлорофилла в различных видах растения рода Urtica [6, 12-19]

\begin{tabular}{|c|c|c|c|c|}
\hline $\begin{array}{l}\text { № } \\
\Pi / \Pi \\
\end{array}$ & Вид крапивы & Часть растения & $\begin{array}{c}\text { Метод } \\
\text { определения } \\
\end{array}$ & $\begin{array}{c}\text { Содержание } \\
\text { БАВ, \% }\end{array}$ \\
\hline 1 & 2 & 3 & 4 & 5 \\
\hline \multicolumn{5}{|c|}{ ГКК } \\
\hline 1 & Крапива коноплевая & лист & CФ & $2,03 \pm 0,04$ \\
\hline 2 & Крапива двудомная & лист & СФ & $1,65 \pm 0,04$ \\
\hline 3 & Крапива узколистная & лист & СФ & $1,19 \pm 0,06$ \\
\hline 4 & Крапива жгучая & лист & СФ & $1,60 \pm 0,05$ \\
\hline 5 & Крапива двудомная & лист & СФ & $2,49 \pm 0,0002$ \\
\hline 6 & Крапива двудомная (экспериментальные данные) & лист & $\mathrm{C} \Phi$ & $2,03 \pm 0,02$ \\
\hline \multicolumn{5}{|c|}{ Каротиноиды } \\
\hline 1 & Крапива коноплевая & лист & ФЭК & $0,57 \pm 0,05$ \\
\hline 2 & Крапива двудомная & лист & ФЭК & $0,499 \pm 0,03$ \\
\hline & & & ВЭЖХ & $0,541 \pm 0,05$ \\
\hline
\end{tabular}


Окончание таблицы 3

\begin{tabular}{c|l|c|c|c}
\hline \multicolumn{1}{|c|}{2} & 3 & 4 & 5 \\
\hline 3 & \multicolumn{1}{|c|}{ Крапива двудомная } & трава & СФ & $0,108 \pm 0,001$ \\
4 & Крапива двудомная (экспериментальные данные) & лист & СФ & $0,210 \pm 0,010$ \\
\hline \multicolumn{2}{|c|}{ Хлорофиллы } \\
\hline 1 & Крапива коноплевая & лист & СФ & $0,760 \pm 0,02$ \\
2 & Крапива двудомная & лист & СФ & $6,502 \pm 0,0003$ \\
3 & Крапива двудомная & трава & СФ & $0,2113 \pm 0,0070$ \\
4 & Крапива двудомная (экспериментальные даннье) & лист & СФ & $0,3714 \pm 0,0074$ \\
\hline
\end{tabular}

\section{Выводы}

1. Модифицирована методика прямого спектрофотометрического количественного определения ГКК и хлорофилла. Установлена возможность дополнительного анализа суммы каротиноидов при совместном присутствии в листьях крапивы двудомной за одну аналитическую процедуру.

2. Данные валидационной оценки методики свидетельствуют о возможности ее использования для стандартизации и оценки качества листьев крапивы двудомной.

\section{Список литературы}

1. Киселева Т.Л., Смирнова Ю.А. Лекарственные растения в мировой медицинской практике: государственное регулирование номенклатуры и качества. М., 2009. 295 с.

2. Государственная фармакопея ХІ изд. Вып. 2. М., 1990. С. 274-275.

3. Коломиец Н.Э., Калинкина Г.И., Сапронова Н.Н. Стандартизация листьев крапивы двудомной // Фармация. 2011. №6. C. 22-24.

4. Георгиевский В.П., Комисаренко Н.Ф., Дмитрук С.Е. Биологически активные вещества лекарственных растений. Новосибирск, 1990. 333 с.

5. Федосеева Г.М., Пецуха В.С. Количественное определение витаминов в листьях крапивы коноплевой // Сборник научных трудов: «Фармация из века в век. Анализ и стандартизация лекарственных средств». Ч. III. СПб., 2008. C. $170-172$.

6. Копытько Я.Ф., Лапинская Е.С., Сокольская Т.А. Применение, химический состав и стандартизация сырья и препаратов Urtica // Химико-фармацевтический журнал. 2011. Т. 45, №10. С. 32-40.

7. Землянухин А.А., Землянухин Л.А. Большой практикум по физиологии и биохимии растений. Воронеж, 1996. $188 \mathrm{c}$.

8. Струсовская О.Г. Определение пигментного состава Cochlearia officinalis, произрастающей на островах Соловецкого архипелага // Фармация и общественное здоровье : матер. V Междунар. конф. Екатеринбург, 2012. C. $184-187$.

9. Антонов В.И., Ягодин В.И. Спектральные характеристики препаратов хлорофилла из еловой древесной зелени // Химия растительного сырья. 2006. №2. С. 47-49.

10. Тринеева О.В., Воропаева С.С., Сливкин А.И. Исследование спектральных характеристик извлечений из листьев крапивы двудомной // Фармобразование-2013 : матер. 5-й Всеросс. с междунар. участием научнометод. конф. Воронеж, 2013. Часть II. С. 546-549.

11. Патент №2531940 (РФ). Способ спектрофотометрического количественного определения хлорофилла, каротиноидов и гидроксикоричных кислот в листьях крапивы двудомной при совместном присутствии / О.В. Тринеева, Е.Ф. Сафонова, С.С. Воропаева, А.И. Сливкин. 2014.

12. Лупинская С.М., Орехова С.В., Васильева О.Г. Изучение биологически активных веществ липы, крапивы и душицы и сывороточных экстрактов на их основе // Химия растительного сырья. 2010. №3. С. 143-145.

13. Белякова А.В., Вайнштейн В.А., Маркова К.В. и др. Применение синтетических эфиров высших жирных кислот для экстрагирования листьев крапивы // Химико-фармацевтический журнал. 2005. Т. 39, №11. С. 35-39.

14. Пецуха B.C. Фармакогностическое изучение крапивы коноплевой (Urtica cannabina L.) : автореф. дис. ... канд. фарм. наук. Улан-Удэ, 2009. 26 с.

15. Ушанова В.М., Лебедева О.И., Репях С.М. Исследование влияния условий произрастания на химический состав крапивы двудомной // Химия растительного сырья. 2001. №3. С. 97-104.

16. Матюшенко Н.В. Влияние условий сушки на содержание флавоноидов и гидроксикоричных кислот в листьях крапивы узколистной // Разработка, исследование и маркетинг новой фармацевтической продукции : сб. науч. трудов. Пятигорск, 2012. С. 78-79.

17. Яцюк В.Я., Чалый Г.А., Сошникова О.В. Биологически активные вещества травы крапивы двудомной // Российский медико-биологический вестник имени академика И.П. Павлова. 2006. №1. С. 25-29.

18. Скалозубова Т.А. Изучение метаболома сырья и лекарственных форм крапивы двудомной : автореф. дис. ... канд. фарм. наук. М., 2013. 23 с.

19. Сошникова О.В. Изучение химического состава и биологической активности растений рода крапива : автореф. дис. ... канд. фарм. наук. Курск, 2006. 22 с.

Поступило в редакциию 20 октября 2014 г.

После переработки 9 июня 2015 г. 
Trineeva O.V.*, Slivkin A.I., Safonova E.F. DETERMINATION OF HYDROXYCINNAMIC ACIDS, CAROTENOIDS AND CHLOROPHYLL IN THE LEAVES OF STINGING NETTLE (URTICA DIOICA L.)

Voronezh State University, ul. Studencheskaya, 3, Voronezh, 394006 (Russia), e-mail: trineevaov@mail.ru.

In 2014, it approved a new pharmacopoeia articles for inclusion in the State Pharmacopoeia XIII ed. «Nettle leaves», which, by analogy with the European Pharmacopoeia provides quantification of hydroxycinnamic acids in terms of chlorogenic acid. The value for nettle leaves are biologically active substances such as vitamin $\mathrm{K}$, flavonoids, hydroxycinnamic acids, carotenoids, tannins, amino acids, and other chlorophylls. Nettle leaves are rich in carotenoids, the absorption maximum of which is clearly seen in the spectra of the extracts. It was based on the previously developed method for the quantitative determination of hydroxycinnamic acids and chlorophyll in the leaves of nettle by spectrophotometry. However, the form of the absorption spectrum of the analyte extracting raw indicates the possibility of simultaneous determination of not only the data of biologically active substances, but also without prior separation of carotenoids, because their peaks do not overlap. The work carried out modification techniques quantitative content of hydroxycinnamic acids and chlorophyll in the leaves of nettle by spectrophotometry, which consists in determining the amount of additional carotenoids in terms violoksantin when present together. The influence of the polarity of the extractant to extract the studied groups of biologically active substances. It was found that with increasing polarity to 6.0 units is an increase in extractable all studied groups of substances. Established validation characteristics quantifying carotenoids on the proposed methodology. A comparative analysis of the obtained results with published data to identify the studied groups of biologically active substances of different kinds of plants of the genus Urtica ssp.

Keywords: nettle (Urtica dioica), standardization, hydroxycinnamic acids, chlorophyll, violoksantin.

\section{References}

1. Kiseleva T.L., Smirnova Ju.A. Lekarstvennye rastenija v mirovoj medicinskoj praktike: gosudarstvennoe regulirovanie nomenklatury $i$ kachestva. [Medicinal plants in the world medical practice: state regulation of the range and quality]. Moscow, 2009, 295 p. (in Russ.).

2. Gosudarstvennaja farmakopeja XI izd. [State Pharmacopoeia XI Ed.], vol. 2, Moscow, 1990, pp. 274-275. (in Russ.).

3. Kolomiec N.Je., Kalinkina G.I., Sapronova N.N. Farmacija, 2011, no. 6, pp. 22-24. (in Russ.).

4. Georgievskij V.P., Komisarenko N.F., Dmitruk S.E. Biologicheski aktivnye veshhestva lekarstvennyh rastenij. [Biologically active substances of medicinal plants]. Novosibirsk, 1990, 333 p. (in Russ.).

5. Fedoseeva G.M., Pecuha V.S. Sbornik nauchnyh trudov: «Farmacija iz veka v vek. Analiz $i$ standartizacija lekarstvennyh sredstv». Chast' III. [Collection of scientific papers: "Pharmacy from century to century. Analysis and standardization of drugs ". Part III]. Saint Petersburg, 2008, pp. 170-172. (in Russ.).

6. Kopyt'ko Ja.F., Lapinskaja E.S., Sokol'skaja T.A. Himtko-farmacevticheskij zhurnal, 2011, vol. 45, no. 10, pp. 32-40. (in Russ.).

7. Zemljanuhin A.A., Zemljanuhin L.A. Bol'shoj praktikum po fiziologii i biohimii rastenij. [Large workshop on Plant Physiology and Biochemistry]. Voronezh, 1996, 188 p. (in Russ.).

8. Strusovskaja O.G. Materialy V mezhdunarodnoj konferencii «Farmacija i obshhestvennoe zdorov'e». [Proceedings of the V International Conference "Pharmacy and Public Health"]. Ekaterinburg, 2012, pp. 184-187. (in Russ.).

9. Antonov V.I., Jagodin V.I. Himija rastitel'nogo syr'ja, 2006, no. 2, pp. 47-49. (in Russ.).

10. Trineeva O.V., Voropaeva S.S., Slivkin A.I. Materialy 5-oj Vserossijskoj s mezhdunarodnym uchastiem nauchnometodicheskoj konferencii «Farmobrazovanie - 2013». Chast' II. [Proceedings of the 5th All-Russia with international participation Scientific Conference "Farmobrazovanie - 2013". Part II.]. Voronezh, 2013, pp. 546-549. (in Russ.).

11. Patent N2531940 (RU). 2014. (in Russ.).

12. Lupinskaja S.M., Orehova S.V., Vasil'eva O.G. Himija rastitel'nogo syr'ja, 2010, no. 3, pp. 143-145. (in Russ.).

13. Beljakova A.V., Vajnshtejn V.A., Markova K.V. i dr. Himiko-farmacevticheskij zhurnal, 2005, vol. 39, no. 11. pp. 35-39. (in Russ.).

14. Pecuha V.S. Farmakognosticheskoe izuchenie krapivy konoplevoj (Urtica cannabina L.): avtoref. dis. kand. farm. $n$. [Farmakognostichesky studying Konopleva nettle (Urtica cannabina L.) : author. dis. the candidate of pharmaceutical sciences.]. Ulan-Udje, 2009. 26 p. (in Russ.).

15. Ushanova V.M., Lebedeva O.I., Repjah S.M. Himija rastitel'nogo syr'ja, 2001, no. 3, pp. 97-104. (in Russ.).

16. Matjushenko N.V. Sbornik nauchnyh trudov: «Razrabotka, issledovanie i marketing novoj farmacevti-cheskoj produkcii». [Collection of scientific works: "The development, research and marketing of new pharmaceutical products"]. Pjatigorsk, 2012. pp. 78-79. (in Russ.).

17. Jacjuk V.Ja., Chalyj G.A., Soshnikova O.V. Rossijskij mediko-biologicheskij vestnik imeni akademika I.P. Pavlova. 2006, no. 1, pp. 25-29. (in Russ.).

18. Skalozubova T.A. Izuchenie metaboloma syr'ja i lekarstvennyh form krapivy dvudomnoj: avtoref. dis. kand. farm. $n$. [Learning metabolome of raw materials and dosage forms of nettle : author. dis. the candidate of pharmaceutical sciences]. Moscow, 2013, 23 p. (in Russ.).

19. Soshnikova O.V. Izuchenie himicheskogo sostava i biologicheskoj aktivnosti rastenij roda krapiva: avtoref. dis. kand. farm. $n$. [The study of the chemical composition and biological activity of plants of the nettle : author. dis. the candidate of pharmaceutical sciences]. Kursk, 2006, 22 p. (in Russ.).

Received October 20, 2014

Revised June 9, 2015

\footnotetext{
"Corresponding author.
} 